\title{
On the origin of enhanced electrochemical behavior of oxidized activated carbon
}

\author{
Rui Niu, ${ }^{\text {a,c }}$ Haibo Li, ${ }^{\text {b* }}$ Yulong Ma, ${ }^{\text {a,b, }}$
}

a College of Chemistry and Chemical Engineering, Ningxia University, Yinchuan, Ningxia 750021, P.R. China.

b Key Laboratory of Ningxia for Photovoltaic Materials, Ningxia University, Yinchuan, Ningxia750021, P.R. China.

c State Key Laboratory Cultivation Base of Energy Sources and Chemical Engineering, Ningxia University, Yinchuan, Ningxia 750021, P.R. China

* Corresponding author. Fax/Tel: +86 0951 2062414; E-mail: lihaibo@nxu.edu.cn (Haibo Li) 


\begin{abstract}
The amount of ions stored within the electrochemical double layer is dominantly determined by the surface area of porous electrode. High surface area indicates high capacitance. However, this is not the case when the pore is extremely small, less than $1 \mathrm{~nm}$. To observe this phenomenon, we have carried out an experiment by comparatively investigating the electrochemical performance of activated carbon (AC) and sulfuric acid treated AC (SAC). The results show that the electrochemical performance of SAC involving the specific capacitance, rate capability and cycling stability is significantly increased as compared to pristine AC. These are attributed to the improved porosity by differentiating the respective contributions of electrochemical double layer capacity and pseudo-capacity from SAC and AC, respectively.
\end{abstract}

Keywords: Electrochemical double layer, Capacitor, Energy storage, Carbon 


\section{Introduction}

The electrochemical double layer capacitor (EDLC) is a new developed energy storage device that gaining rapidly increasing attentions for completing or replacing batteries. It stores ions within electrical doubles layers formed at electrolyte-electrode interface [1-4]. The EDLC has various advantages of high power, long cycles life and remission environmental pollution [5-7]. Basically, the EDLC is made up of two layers of conductive plates coated with a porous material (eventually becoming positively and negatively charged), separated by an insulator.

According to the principle of EDLC, the amount of charge is closely related to the properties of porous electrode. The porous material ideally has an ultrahigh surface area, suitable pore structure and excellent conductivity [8]. Therefore, carbon and related materials, particularly the activated carbon (AC), are widely utilized as electrode for high performance EDLC due to their high specific surface area, porous structure, low cost, large production, good electrical conductivity and environmental-friendly [9-11]. However, the AC based EDLC often suffers a low capacitance (less than $100 \mathrm{~F} \mathrm{~g}^{-1}$ ) due to low effective surface area (only 17\%) [12]. On the other hand, it is well known that the ultra-high specific surface area of AC is mainly contributed from a large amount of micropore. However, micropore is too small for ions to penetrate and therefore do not participate in ions adsorption. Additionally, double-layer overlap in the micropores might lead to inefficient ion adsorption. Nevertheless, the recent study reveals that the micropore may plays an important role in electrochemical process since an anomalous increase in carbon capacitance at pore sizes less than $1 \mathrm{~nm}$ has been observed [13]. This challenges the long-held axiom that pores smaller than the size of solvated electrolyte ions are incapable of contributing to charge storage.

In the past few decades, the chemical oxidation triggered by acid, i.e. $\mathrm{H}_{2} \mathrm{SO}_{4}$ [14], $\mathrm{HNO}_{3}[15]$ and $\mathrm{H}_{3} \mathrm{PO}_{4}$ [16] etc., is being revealed as one of the most effective alternatives to improve the electrochemical performance of carbons due to its feasibility. Through oxidation, some weakly acidic functional groups, such as $-\mathrm{OH},-\mathrm{NH}_{2}$ and $-\mathrm{COOH}$ are spontaneously coupled with carbon atoms, which may improve the ion exchange ability and introduce weak pseudo reaction. Previously, extensive researches are focus on the 
oxidation, the texture change on porosity and therefore the EDLC performance is more significance.

In this work, the $\mathrm{AC}$ has been treated by sulfuric acid through a facile hydrothermal method. The results show that the pore size of AC shifted after the treatment. Further, the enhanced capacitance of SAC is dominantly contributed from the improved micropore volume and micropore surface area by differentiating the respective contributions from double layer capacitor and pseudo capacitor. Thus, it is believed that this study provides us an alternative way to examine the insight into functionalized carbon based EDLC.

\section{Experimental Section}

\subsection{Synthesis of SAC}

The SAC was prepared by a facile hydrothermal method. At the beginning, $2 \mathrm{~g}$ of AC was dispersed into $25 \mathrm{~mL} 98 \%$ sulfuric acid and then subjected to a hydrothermal reactor at $120{ }^{\circ} \mathrm{C}$ for $10 \mathrm{~h}$. After the mixture was cooled down to the room temperature, $500 \mathrm{~mL}$ distilled water was added, followed by filtrating and rinsing repeatedly using distilled water until the sulfate ion was no longer detected in the product water. After that, the SAC was obtained by simply filtrating through a vacuum filtration system. Finally, the product was placed in an oven for overnight at $80^{\circ} \mathrm{C}$.

\subsection{Fabrication of electrode}

The electrode was fabricated by mixing $80 \%$ of SAC, $10 \%$ of carbon black and $10 \%$ of polyvinylidene fluoride (mass ratio) in ethanol with addition of a few drops of dimethylformamide. Please note that the mixture should be vigorously grinded for several minutes until it became homogenous. Subsequently, the mixtures were casted onto the graphite sheet by a medical blade, followed by drying at $80^{\circ} \mathrm{C}$ for $10 \mathrm{~h}$ in a vacuum oven.

\subsection{Characterization}

The morphology and structure were studied by scanning electron microscopy (SEM, SU8020). The pore size distribution and Brunauer-Emmet-Teller (BET) specific surface area were deduced from the $\mathrm{N}_{2}$ physical adsorption measurement data (AutoChem $\amalg 2920$ ). 
X-Ray photoelectron spectroscopy (XPS, Thermo ESCALAC250Xi) spectra was collected on a monochromatized Al Ka X-ray source $(1486.6 \mathrm{eV})$. The functional groups on SAC were detected by Fourier transform Infrared spectra (FT-IR, TENSOR 27).

\subsection{Electrochemical measurement}

The electrochemical performance including cyclic voltammetry (CV), galvanostatic charging-discharging (GCD) and electrochemical impedance spectroscopy (EIS) were characterized through an electrochemical workstation (CHI 660A) by using three electrodes method in $1 \mathrm{M} \mathrm{KCl}$ aqueous solution. Basically, the SAC, Pt and a saturated calomel electrode were employed as the working electrode, the counter electrode and the reference electrode, respectively. CV measurements were performed at various scan rates ranging from 1 to $100 \mathrm{mV} \mathrm{s}^{-1}$. GCD measurements was carried out in the voltage window of -0.4-0.6 $\mathrm{V}$ at various current densities ranging from 1 to $3 \mathrm{~A} \mathrm{~g}^{-1}$. The specific capacitance $\left(C_{S}\right)$ of $\mathrm{AC}$ and SAC were estimated from $\mathrm{CV}$ and GCD curve based on the below equations, respectively [17]:

$C_{S}=\frac{Q}{\Delta V m}=\frac{\int i d t}{\Delta V m}$

$C_{S}=\frac{i \Delta t}{m \Delta V}$

Where $Q$ is the voltammetric charge in one sweep $(\mathrm{C}), \Delta V$ is the potential window (1.0 V), $m$ is the mass $(\mathrm{g})$ of the sample being coated on the graphite electrode, $v$ is the scan rate (V $\mathrm{s}^{-1}$ ), $i$ is the current (A) used for charging-discharging, $\Delta t$ is the time for average of charge-discharge. Therefore the specific energy density $\left(S E, \mathrm{Wh} \mathrm{kg}^{-1}\right)$ and the specific power density ( $S P, \mathrm{~W} \mathrm{~kg}^{-1}$ ) can be separately obtained from equations (3) and (4) [17].

$$
\begin{aligned}
& S E=\frac{1000 C_{S, T}(\Delta V)^{2}}{7200} \\
& S P=\frac{3600 S E}{t}
\end{aligned}
$$

\section{Results and Discussion}

Fig.1 (a), (b) and (c), (d) show the SEM image of AC and SAC in low and high magnifications, respectively. Obviously, both AC and SAC exhibit rock like shape with a 
large number of holes. Meanwhile, it can be seen that the surface of SAC is smoother than that of AC. These are mainly resulted from the dehydration by sulfuric acid.

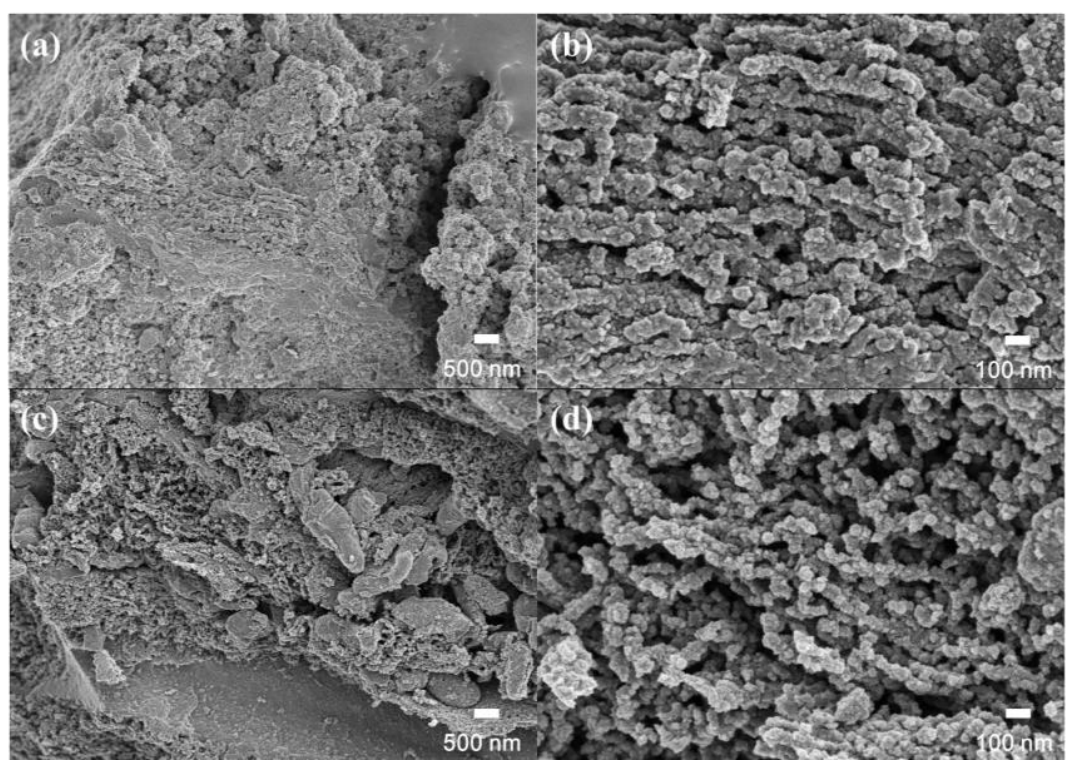

Fig. 1 SEM images of (a), (b) AC and (c), (d) SAC in different magnifications

The $\mathrm{N}_{2}$ adsorption-desorption isotherm and corresponding pore size distribution of $\mathrm{AC}$ and SAC are presented in Fig.2 (a) and (b), respectively. They exhibit representative type Icurves with obvious capillary condensation steps above $\mathrm{P} / \mathrm{P}_{\mathrm{o}}=0.4$, implying the existence of mesopores which guarantees a huge space for ion accommodation. Furthermore, the texture parameters associated with AC and SAC are summarized in Table 1. The BET surface area of AC and SAC are 1477.2 and $1244.7 \mathrm{~m}^{2} \mathrm{~g}^{-1}$, respectively. Accordingly, the microspores volume and surface area of AC and SAC are $0.17,0.22 \mathrm{~m}^{3}$ $\mathrm{g}^{-1}$ and 336.5 and $411.8 \mathrm{~m}^{2} \mathrm{~g}^{-1}$. These values demonstrate that the sulfating do not change the pore texture of AC except for introducing more microspores.
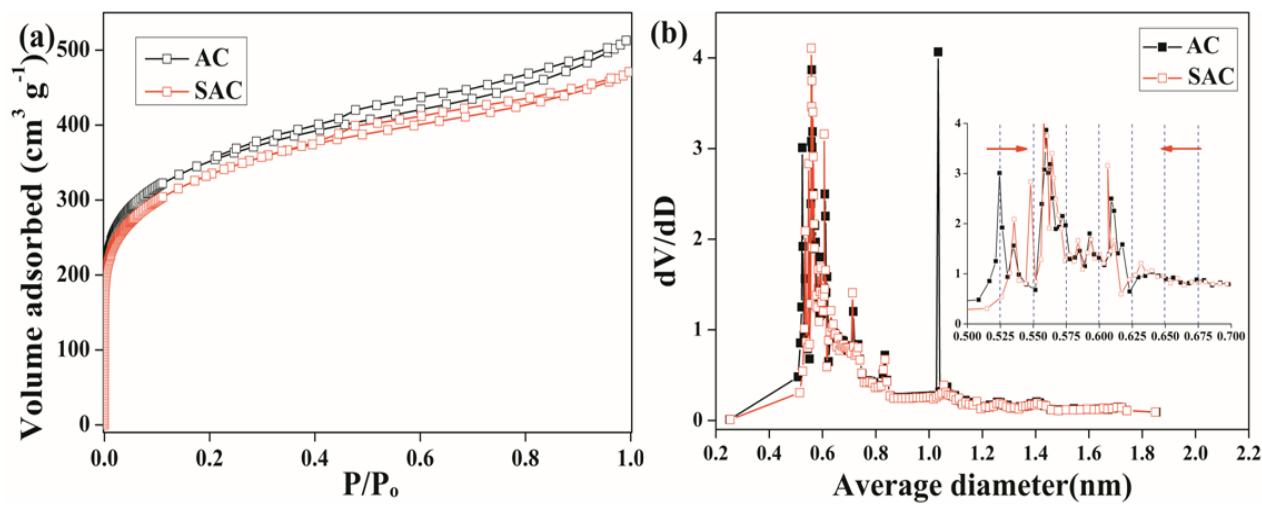

Fig. 2 (a) Nitrogen adsorption-desorption isotherms of AC and SAC, (b) pore size distribution. 
Table 1 Porosity texture of AC and SAC

\begin{tabular}{ccccc}
\hline Sample & $\mathrm{S}_{\text {BET }}\left(\mathrm{m}^{2} \mathrm{~g}^{-1}\right)$ & $\mathrm{V}_{\text {micropore }}\left(\mathrm{cm}^{3} \mathrm{~g}^{-1}\right)$ & $\mathrm{S}_{\text {micropore }}\left(\mathrm{m}^{2} \mathrm{~g}^{-1}\right)$ & $\mathrm{D}_{\text {averagepore }}(\mathrm{nm})$ \\
\hline AC & 1477.2 & 0.17 & 336.5 & 0.17 \\
SAC & 1244.7 & 0.22 & 411.8 & 0.17 \\
\hline
\end{tabular}

FTIR spectra shown in Fig.3 (a) is recorded to evaluate the functional groups. The FTIR spectrum of AC shows three intense bands at $3428 \mathrm{~cm}^{-1}, 1632 \mathrm{~cm}^{-1}$ and $1132 \mathrm{~cm}^{-1}$, which are assigned to $-\mathrm{O}-\mathrm{H}$ stretching vibration of hydroxylic groups [10], $-\mathrm{C}=\mathrm{O}$ stretching vibration of carbonyl groups [18] and -C-O stretching vibration [11], respectively. Remarkably, there are three new peaks at $1388 \mathrm{~cm}^{-1}, 1013 \mathrm{~cm}^{-1}$ and $618 \mathrm{~cm}^{-1}$ appearing on $\mathrm{SAC}$ spectrum as compared to pristine $\mathrm{AC}$, in which the peak at $1388 \mathrm{~cm}^{-1}$ is attributed to -O-H bending vibration [19] while the peak at $1013 \mathrm{~cm}^{-1}$ and $618 \mathrm{~cm}^{-1}$ confirm the presence of $-\mathrm{SO}_{3} \mathrm{H}[20,21]$. It is necessary to mention that the intense water containing groups as well as $-\mathrm{O}-\mathrm{H}$ and $-\mathrm{SO}_{3} \mathrm{H}$ are beneficial to improve the hydrophilicity of SAC, resulting in better electrochemical effective interface and therefore the performance. The XPS spectrum of AC and SAC depicted in Fig.3 (b), (c) and (d) are employed to examine the insight into chemical bond. It can be observed from the Fig.3 (b) that the SAC exhibits C1s, O1s and S2p, indicating the successfully doping of sulfur. Fig.3 (c) shows the C1s peak of AC and SAC. The broad carbon peaks are observed in the binding energy ranging from 282 to $292 \mathrm{eV}$. Deconvolution of the C1s spectra of AC and SAC could generate five peaks at $284.8,286.2,287.8,289.1$, and $291.0 \mathrm{eV}$, corresponding to $\mathrm{C}-\mathrm{C}$ or $\mathrm{C}=\mathrm{C}, \mathrm{C}-\mathrm{O}$ or $\mathrm{C}=\mathrm{N}$ or $\mathrm{C}-\mathrm{S}, \mathrm{C}=\mathrm{O}, \mathrm{O}-\mathrm{C}=\mathrm{O}$, and $\pi-\pi^{*}[10,14,22,23]$, respectively. Fig.3 (d) shows the S2p spectra of AC and SAC. As compared to AC, the S2p peak of SAC can be divided into two doublets having different binging energies: one doublet with lower binging energy arising from electron-rich $\left(2 \mathrm{p}^{2 / 3}\right)$ sulfur, and another with higher binging energy arising from electron-poor $\left(2 \mathrm{p}^{1 / 2}\right)$ sulfur, which is mainly caused by different environments around sulfur atoms [14,21]. Table 2 summarizes the intensities of various peaks in terms of corresponding components. The intensity of the peak at $286.2 \mathrm{eV}$ is enhanced after the treatment due to the involvement of $\mathrm{C}-\mathrm{SO}_{3} \mathrm{H}$ or $\mathrm{C}-\mathrm{OSO}_{3} \mathrm{H}$. In contrast, the intensity of the peak at $289.1 \mathrm{eV}$ is decreased. This is probably attributed to the fact that the sulfuric acid 
react with $\mathrm{O}-\mathrm{C}=\mathrm{O}$ yielding $-\mathrm{O}-\mathrm{SO}_{3} \mathrm{H}[14]$. According to the literature [14], it is recognized that the $\mathrm{H}^{+}$derived from the $-\mathrm{SO}_{3} \mathrm{H}$ or $-\mathrm{OSO}_{3} \mathrm{H}$ is possibly to exchange with $\mathrm{K}^{+}$during the electrochemical process and thereby enhance the specific capacitance.
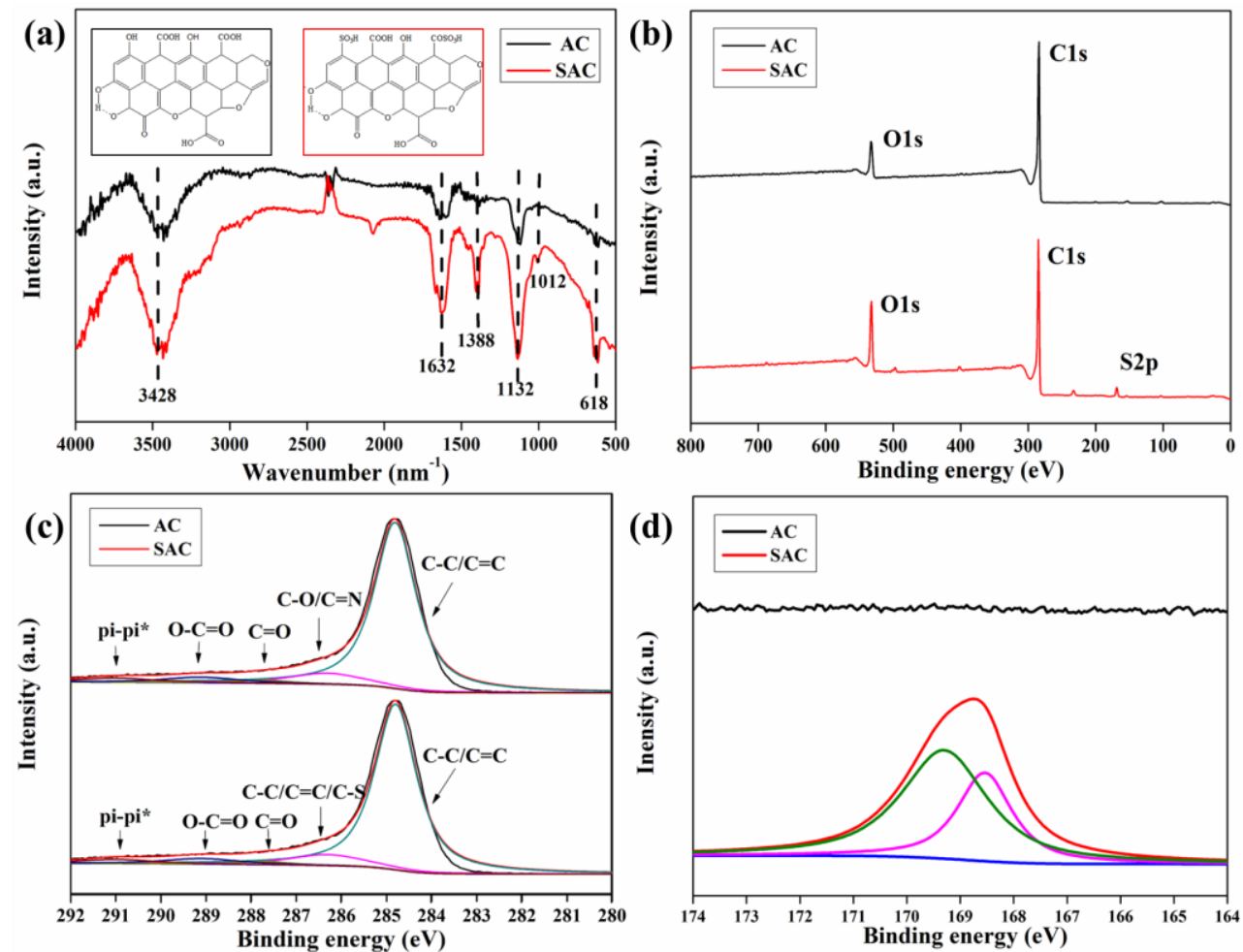

Fig. 3 (a) FT-IR, (b) XPS, (c) C1s and (d) S2p spectra of AC and SAC.

Table 2 XPS data of AC and SAC

\begin{tabular}{|c|c|c|c|}
\hline \multirow{2}{*}{ Sample } & \multirow{2}{*}{ Peak position $(\mathrm{eV})$} & \multicolumn{2}{|c|}{ Percentage $(\%)$} \\
\hline & & $\mathrm{AC}$ & SAC \\
\hline \multirow{5}{*}{$\mathrm{C} 1 \mathrm{~s}$} & $284.8(\mathrm{C}-\mathrm{C} / \mathrm{C}=\mathrm{C})$ & 79.94 & 78.68 \\
\hline & $286.2(\mathrm{C}-\mathrm{O} / \mathrm{C}=\mathrm{N} / \mathrm{C}-\mathrm{S})$ & 9.65 & 10.66 \\
\hline & $287.8(\mathrm{C}=\mathrm{O})$ & 1.84 & 2.92 \\
\hline & $289.1(\mathrm{O}-\mathrm{C}=\mathrm{O})$ & 4.89 & 3.06 \\
\hline & $291.0\left(\pi-\pi^{*}\right)$ & 3.68 & 4.78 \\
\hline \multirow{2}{*}{$\mathrm{S} 2 \mathrm{p}$} & $168.5\left(2 \mathrm{p}^{1 / 2}\right)$ & \multicolumn{2}{|c|}{34.18} \\
\hline & $169.3\left(2 \mathrm{p}^{2 / 3}\right)$ & \multicolumn{2}{|c|}{65.82} \\
\hline
\end{tabular}

The CV curves of SAC measured at scan rate ranging from 1 to $100 \mathrm{mV} \mathrm{s}^{-1}$ in $1 \mathrm{M} \mathrm{KCl}$ solution within potential window of -0.4-0.6 V are showed in Fig.4 (a). Regardless of the 
scan rate, the $\mathrm{CV}$ curves of SAC show an almost rectangular shape without redox peak, indicating the SAC has an ideal capacitive behavior. According to Eq. (1), the Cs can be obtained and depicted in Fig.4 (b). At each scan rate, the Cs of SAC is much larger than that of AC, evidencing the improved EDLC performance. For comparison, the capacitance of SAC electrode was $232 \mathrm{~F} \mathrm{~g}^{-1}$ whereas the $\mathrm{AC}$ was $219 \mathrm{~F} \mathrm{~g}^{-1}$ at the scan rate of $1 \mathrm{mV} \mathrm{s}^{-1}$, showing an incensement of $6 \%$. When the scan rate was increased from 1 to $100 \mathrm{mV} \mathrm{s}^{-1}$, the $C s$ of $\mathrm{AC}$ decreased from 219 to $75 \mathrm{~F} \mathrm{~g}^{-1}$ with a drop by $\sim 66 \%$. In contrast, the $C s$ of the SAC electrode only dropped by $\sim 35 \%$ from 232 to $150 \mathrm{~F} \mathrm{~g}^{-1}$, indicating better scan rate dependence.

The GCD curve of SAC are shown in Fig.4 (c). Obviously, all the curves are symmetrical and linear continuous at different current densities from $1 \mathrm{~A} \mathrm{~g}^{-1}$ to $3 \mathrm{~A} \mathrm{~g} \mathrm{~g}^{-1}$, indicating that the electrode has excellent electrochemical reversibility and charge-discharge quality. Meanwhile, the $\mathrm{iR}$ drop is very small at $3 \mathrm{~A} \mathrm{~g}^{-1}$, implying better conductivity of SAC. The Cs of AC and SAC electrode obtained from the GCD process according to Eq. (2) were depicted in Fig.4 (d) for comparison. It can be clearly seen that $C_{S}$ decreased as the current density ranging from 1 to $3 \mathrm{~A} \mathrm{~g}^{-1}$. When the current density was increased from 1 to $3 \mathrm{~A} \mathrm{~g}^{-1}$, the $C s$ of AC electrode decreased from 67.0 to $40.5 \mathrm{~F} \mathrm{~g}^{-1}$ with a drop by $\sim 40 \%$. In contrast, the $C s$ of SAC electrode only dropped by $\sim 17 \%$ from 111.1 to $91.8 \mathrm{~F} \mathrm{~g}^{-1}$, demonstrating the better electrochemical behavior.
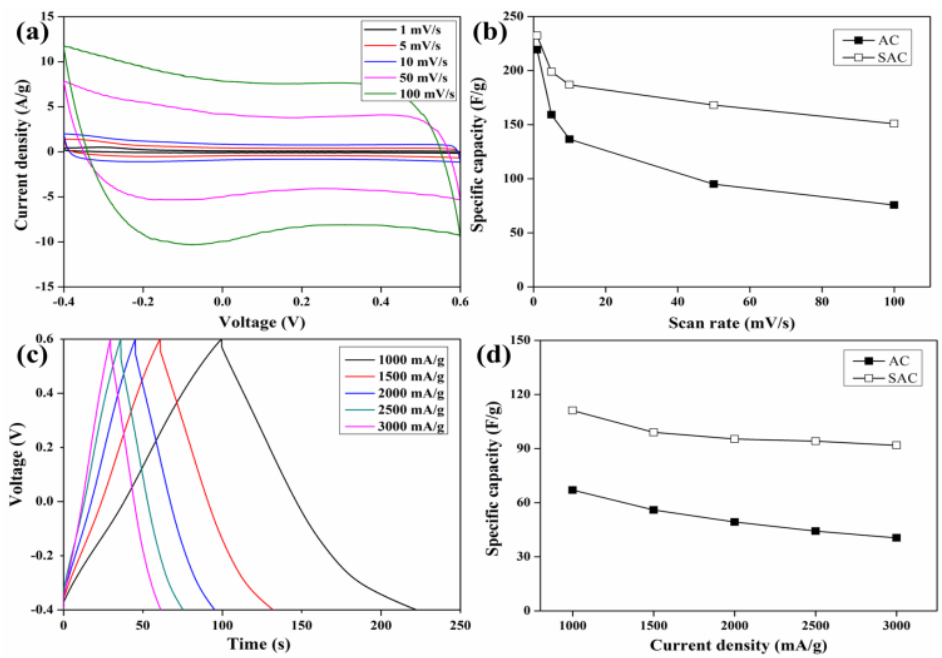

Fig. 4 (a) CV curves of SAC at various scan rates, (b) mass normalized specific capacitance of AC and SAC with respect to the scan rates, (c) GCD curves of SAC under 
different current densities, (d) gravimetric capacitance of AC and SAC with respect to the current density.

Previously, it is well known that the pores smaller than the size of solvated electrolyte ions are incapable of contributing to charge storage. However, Chmiloa et al have explored the impact of pore size on the electrochemical performance of carbons [13]. Their findings classified three pore size distribution areas, in which the dependence of normalized capacitance on average pore size is different (referring to Fig.5). When pores were substantially larger than twice the size of the solvated ions, there was a contribution to capacitance from compact layers of ions residing on both adjacent pore walls. In this case, the capacitance is proportional to surface area (Fig.5 (a)). When the pore size is decreased less than twice the solvated ion size, it would reduce the normalized capacitance because compact on layers from adjacent pore walls impinged and the surface area usable for double layer formation was reduced (Fig.5 (b)). This trend reversed with a further decrease in the pore size to less than that of the solvated ion size. Decreasing the pore size to a value approaching the crystal graphic diameter of the ion would result in $100 \%$ increase in normalized capacitance (Fig.5 (c)). From table 1, it is read that the $\mathrm{V}_{\text {micropore }}$ and $\mathrm{S}_{\text {micropore }}$ of SAC are larger than that of AC (Fig.5 (d) and (e)). Thus, SAC may provide as much as tunnels for penetrating ions.
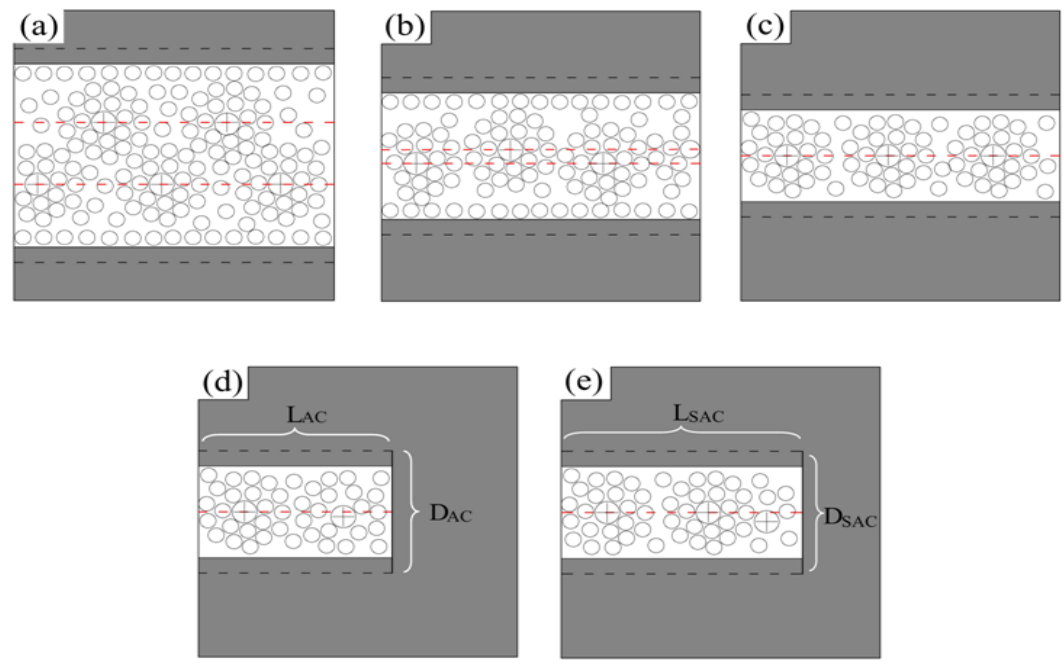

Fig. 5 Drawing of solvated ions residing in pores with distance between adjacent pore walls (a) greater than $2 \mathrm{~nm}$, (b) between 1 and $2 \mathrm{~nm}$, (c) less than $1 \mathrm{~nm}$, (d) AC, and (e) SAC 
To solid our explanation, it is possible to compare the respective contribution of pseudocapacitance from AC and SAC, respectively. According to the studies by Trasstti et al. [24], the outer electrochemical surface, estimated from the outer charge $\left(q_{o}^{*}\right)$, corresponds to the region touching the electrolyte directly; the inner electrochemical surface, estimated from the inner charge $\left(q_{i}{ }^{*}\right)$, indicates the regions of pores, grain boundaries, crevices, and crack, etc. So, the $C_{o}{ }^{*}$ can be gained from the extrapolation of $C^{*}$ to $v=\infty$ from the plots of $C^{*} v s . v^{-1 / 2}$ (see Fig.6 (a)), the total charge $\left(C_{t}^{*}\right)$ can be estimated from the extrapolation of $C^{*}$ to $v=0$ from the plots of $1 / C^{*} v s$. $v^{1 / 2}$ (see Fig.6 (b)). Accordingly, the $C_{i}{ }^{*}$ can be obtained from the difference between $C^{*}$ and $C_{t}{ }^{*}$. Hence, $C_{t}{ }^{*}$, $C_{o}{ }^{*}$ and $C_{i}{ }^{*}$ are summarized in Table 3 . Due to the abundant presence of oxygen-containing functional groups, $69.99 \%$ of $C_{i}{ }^{*}$ comes from the pseudo-capacitance for AC. However, the corresponding percentage is only $32.60 \%$ for SAC, implying that the improved specific capacitance of SAC is mainly contributed from the double layer capacitance.
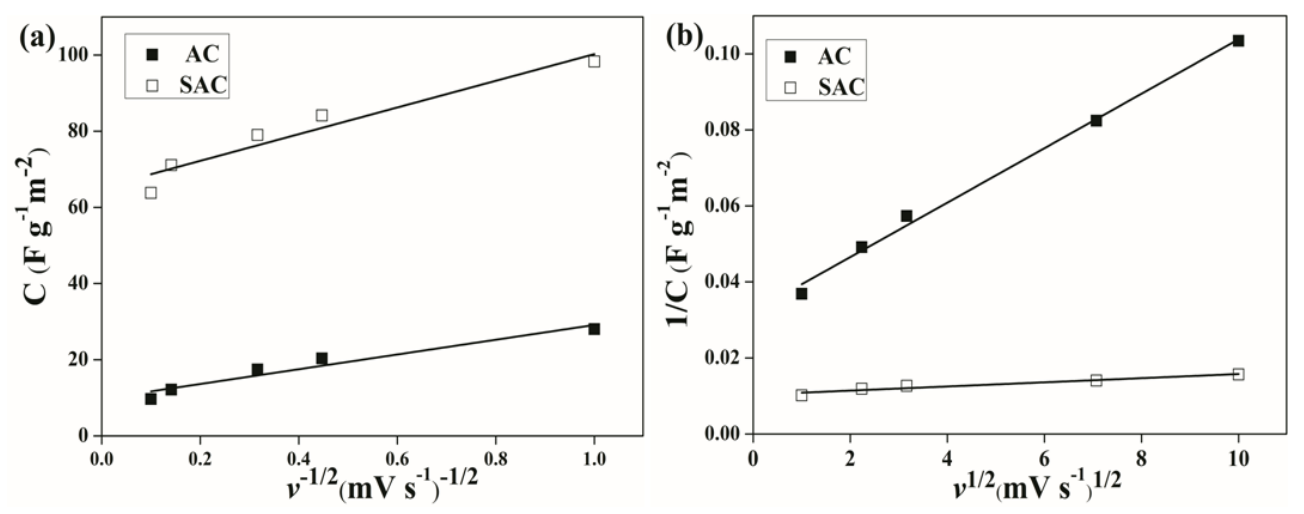

Fig. 6 Dependence of (a) $C^{*}$ on $v^{-1 / 2}$ and (b) $1 / C^{*}$ on $v^{1 / 2}$ for $\mathrm{AC}$ and $\mathrm{SAC}$

Table 3 The total capacity $\left(C_{t}{ }^{*}\right)$, outer capacity $\left(C_{o}{ }^{*}\right)$ and inner capacity $\left(C_{i}{ }^{*}\right)$ for $\mathrm{AC}$ and SAC

\begin{tabular}{ccccc}
\hline Sample & $C_{t}{ }^{*}$ & $C_{o}{ }^{*}$ & $C_{i}{ }^{*}$ & $C_{i}{ }^{*} / C_{t}{ }^{*}$ \\
\hline AC & 31.01 & 9.76 & 21.25 & 68.53 \\
SAC & 96.80 & 65.20 & 31.60 & 32.65 \\
\hline
\end{tabular}

Enable to understand the EDLC power performance of SAC electrode, the kinetic features of the ion diffusion inside of the porous electrode was investigated using EIS. Fig.7 show the Nyquist plot at the frequency range from $0.01 \mathrm{kHz}$ to $100 \mathrm{kHz}$ for both AC and SAC electrodes with an enlarged plot for the high-frequency region and equivalent 
circuit in the inset. The EIS composed of an almost vertical line in the low-frequency region indicates a good capacitive behavior and a small semicircle in the high-frequency region which from the double layer capacitance $\left(C_{d l}\right)$ in parallel with the overall contact impedance $\left(R_{c t}\right)$ produced by the electrical connection and the charge transfer at the contact interface. Otherwise, the $R_{c t}$ represents overall diffusion generated from the electrolyte ions diffuse in the electrode surface and diffusion of the exchange process and electrolyte. Through simulating equivalent circuit, it can be obtained that the $C_{d l}$ value of $\mathrm{AC}$ and SAC are 0.06063 and $0.1172 \mathrm{~F} \mathrm{~cm}^{-2}$. Meanwhile, the SAC exhibits contact impedance of $1560 \Omega \mathrm{cm}^{2}$, which is higher than the value of AC $\left(219 \Omega \mathrm{cm}^{2}\right)$. On the other hand, the $R_{c t}$ value of SAC is $9.053 \Omega \mathrm{cm}^{2}$, which is also higher than the corresponding value of AC $\left(5.953 \Omega \mathrm{cm}^{2}\right)$. These are ascribed to longer diffusion distance within the enlarged micropore space (referring to the $\mathrm{N}_{2}$ adsorption-desorption results).

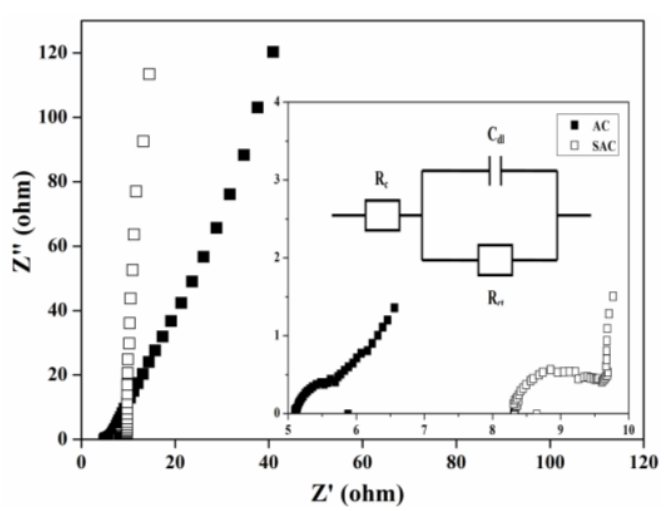

Fig. 7 Nyquist plot of the EIS of the AC and SAC electrodes, the inset shows the high frequency region of the plot and the equivalent circuit

The Ragone plot of the estimated specific energy and specific power for AC and SAC electrode at various charge-discharge current densities are showed in Fig.8 (a). As can be observed from the figure, the specific energy of the SAC electrode is much higher than that of AC electrode at each specific power density. Regarding to SAC electrode, as the specific power density increases from 0.56 to $1.5 \mathrm{~kW} \mathrm{~kg}^{-1}$, the specific energy drops from 15.43 to $12.75 \mathrm{Wh} \mathrm{kg}^{-1}$. On the other hand, the cycles stability of the SAC electrode was tested by continuous charge-discharge measurement in potential windows ranging from $-0.4 \mathrm{~V}$ to $0.6 \mathrm{~V}$ at a current density of $2 \mathrm{~A} \mathrm{~g} \mathrm{~g}^{-1}$. Fig. 8 (b) shows the cycling performance of 
SAC electrode. As shown, the SAC electrode remained $85 \%$ capacity retention after 400 charge-discharge cycles, exhibiting good cycle ability.
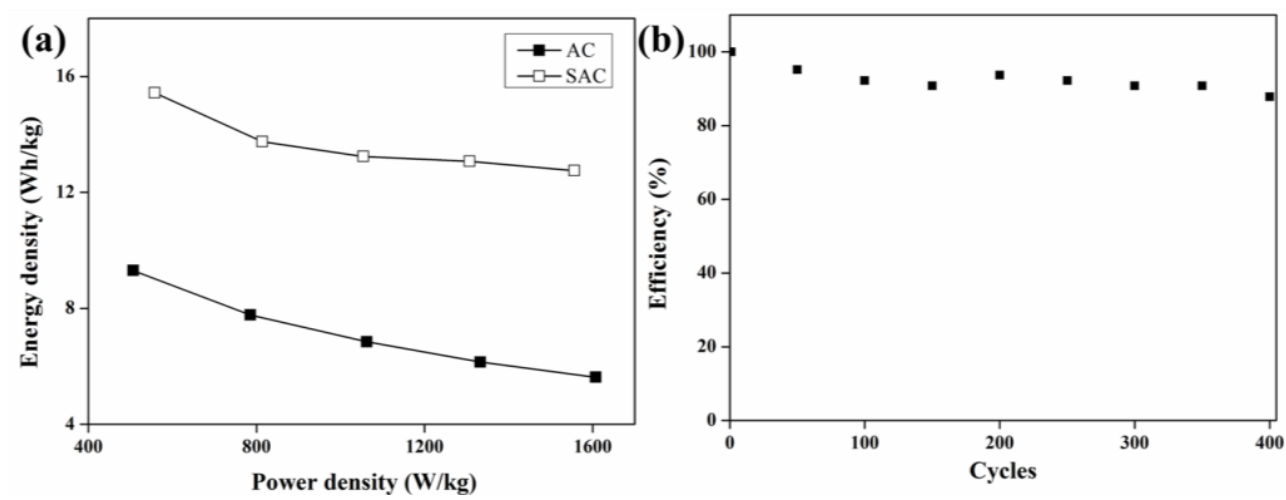

Fig. 8 (a) Ragone plot of the estimated specific energy and specific power for AC and SAC electrode at various charge-discharge current densities. (b) Charge-discharge cycling test of the SAC electrode at a current of $2 \mathrm{~A} \mathrm{~g}^{-1}$ for 400 cycles

\section{Conclusions}

In this work, the sulfuric acid oxidized activated carbon (SAC) has been prepared for electrochemical double layer capacitor (EDLC). The electrochemical results show that the SAC has an improved electrochemical performance, i.e. specific capacitance and energy density, by compare to that of AC. Further, by calculating the respective contributions of double layer capacity and pseudo-capacity from AC and SAC, it is demonstrated that the improved micropore volume and surface are account for the enhanced EDLC performance.

\section{Acknowledgements}

This research is supported by National Science Foundation of China (No.21403120), Research Starting Funds for Imported Talents, Ningxia University and National Basic Research Program of China (973 Program, No.2012CB723106).

\section{References}

[1] H. B. Li, Y. Wang, Y. M. Shi, J. Li, L. J. He, H. Y. Yang, RSC Adv. 3 (2013) 14954.

[2] T. Mitome, Y. Uchida, Y. Egashira, N. Nishiyama, Colloid Surf A Physicochem Eng Asp. 449 (2014) 51.

[3] Y. Okabe, Y. Suda, H. Tanoue, H. Takikawa, H. Ue, K. Shimizu, Electrochim Acta. 131 (2014) 207. 
[4] J. R. Miller, R. A. Outlaw, B. C. Holloway, Science. 329 (2010) 1637.

[5] M. F. Shukur, R. Ithnin, M. F. Z. Kadir, Electrochim Acta. 136 (2014) 204.

[6] T. Tojo, K. Sakurai, H. Muramatsu, T. Hayashi, K. S. Yang, Y. C. Jung, C. M. Yang, M. Endo, Y. A. Kim, RSC Adv. 4 (2014) 62678.

[7] W. Lu, G. Yushin, Carbon. 49 (2011) 4830.

[8] C. H. Kim, B. H. Kim, J. Electroanal Chem. 730 (2014) 1.

[9] X. Y. Zhao, S. S. Huang, J. P. Cao, S. C. Xi, X. Y. Wei, J. Kamamoto, T. Takarada, J Anal Appl Pyrolysis. 105 (2014) 116.

[10] W. Huang, Y. M. Zhang, S. X. Bao, R. Cruz, S. X. Song, Desalination. 340 (2014) 67.

[11] X. J. He, Y. J. Geng, J. S. Qiu, M. D. Zheng, S. Long, X. Y. Zhang, Carbon. 48 (2010) 1662.

[12] P. M. Biesheuvel, B. van Limp, A. van der Wal, Phys Chem C. 3 (2009) 5636.

[13] J. Chmiola, G. Yushin, Y. Gogotsi, C. Portet, P. Simon, P. L. Taberna, Science. 313 (2006) 1760.

[14] Y. J. Kim, H. J. Lee, S. W. Lee, B. W. Cho, C. R. Park, Carbon. 43 (2005) 163.

[15] G. T. K. Fey, K. L. Chen, Y. C. Chang, Mater Chem Phys. 76 (2002) 1.

[16] Y. Nakagawa, M. Molina-Sabio, F. Rodríguez-Reinoso, Micropor Mesopor Mat. 103 (2007) 29.

[17] Y. H. Lee, K. H. Chang, C. C. Hu, J Power Sources. 227 (2013) 300.

[18] K. Wasiński, M. Walkowiak, G. Lota, J Power Sources. 255 (2014) 230.

[19] D. C. Vennerberg, R. L. Quirino, Y. Jang, M. R. Kessler, ACS Appl Mater Interf. 6 (2014) 1835.

[20] X. Z. Liang, M. F. Zeng, C. Z. Qi, Carbon. 48 (2010) 1844.

[21] H. Q. Xiao, Y. X. Guo, X. Z. Liang, C. Z. Qi, J Solid State Chem. 183 (2010) 1721.

[22] Y. Wimalasiri, L. Zou, Carbon. 59 (2013) 464.

[23] S. Stankovich, D. A. Dikin, R. D. Piner, K. A. Kohlhaas, A. Kleinhammes, Y. Jia, Y. Wu, S. B.

T. Nguyen, R. S. Ruoff, Carbon. 45 (2007) 1558.

[24] S. Ardizzone, G. Fregonara, S. Trasatt, Electrochim Acta. 35 (1990) 263. 